\title{
An NMR [nuclear magnetic resonance] investigation of the chemical association and molecular dynamics in asphalt ridge tar sand ore and bitumen
}

Netzel, D.A.; Coover, P.T.

Sep 1987

Western Research Inst, Laramie, WY (USA)

Reproduced and Distributed by:

U.S. DEPARTMENT OF ENERGY

Office of Scientific and Technical Information

P.O. Box 62

Oak Ridge, TN 37831 


\section{DISCLAIMER}

This report was prepared as an account of work sponsored by an agency of the United States Government. Neither the United States Government nor any agency thereof, nor any of their employees, makes any warranty, express or implied, or assumes any legal liability or responsibility for the accuracy, completeness, or usefulness of any information, apparatus, product, or process disclosed, or represents that its use would not infringe privately owned rights. Reference herein to any specific commercial product, process, or service by trade name, trademark, manufacturer, or otherwise does not necessarily constitute or imply its endorsement, recom. mendation, or favoring by the United States Government or any agency thereof: The views and opinions of authors expressed herein do not necessarily state or reflect those of the United States Government or any agency thereof:

This report has been reproduced directly from the best available copy

Available from the National Technical Information Service, U.S. Department of Commerce, Springfield, Virginia 22161.

Price: Printed Copy AO3

Microfiche AOI

Codes are used for pricing all publications. The code is determined by the number of pages in the publication. Information pertaining to the pricing codes can be found in the current issues of the following publications, which are generally avail able in most libraries: Energy Research Abstracts (ERA), Government Reports Announcements and Index (GR and 1), Scientific and Technical Abstract Reports $(S T$ AR) and publication NTIS. PR 360 avallable from NTIS at the above address. 


\section{DISCLAIMER}

Portions of this document may be illegible in electronic image products. Images are produced from the best available original document. 
DOE/FE/60177-2452

(DE88006578)

Distribution Category UC. 123

AN NMR INVESTIGATION OF THE CHEMICAL ASSOCIATION AND

MOLECULAR DYNAMICS IN ASPHALT RIDGE TAR SAND ORE AND BITUMEN

by

Daniel A. Netzel

Peggy T. Coover

September 1987

Work Performed Under Cooperative Agreement

DE-FC21-83FE60177

For

U.S. Department of Energy

Office of Fossil Energy

Laramie Project office

Laramie, Wyoming

By

Western Research Institute

Laramie, Wyoming 
LIST OF TABLES.................................... i i

LIST OF FIGURES.................................. ii

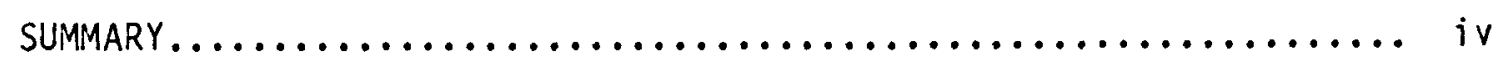

INTRODUCTION....................................... 1

EXPERIMENTAL.................................... 3

Sample Description.............................. 3

Instrumentation................................. 4

RESULTS AND DISCUSSION.............................. 5

Hydrogen $T_{l}$ Values of Related Materials................ 5

Chemical Association Kinetics in Tar Sand Ore and

Bitumen After Thermal Stressing...................... 7

Solvent-Solute (Tar Sand Bitumen) Interactions............... 9

CONCLUSIONS....................................... 12

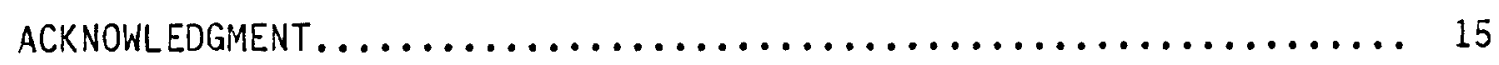

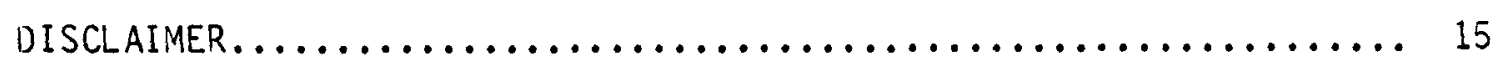

REFERENCES...................................... 15 


\section{LIST OF TABLES}

Table

Page

1. ${ }^{1} H$ Spin-Lattice and Spin-Spin Relaxation Times for Various Materials............................. 6

2. LH Spin-Lattice Relaxation Times After Quenching of Asphalt Ridge Tar Sand Ore and Bitumen Heated to $180^{\circ} \mathrm{C}$

for 1 Hour.

3. $I_{H}$ Spin-Lattice and Spin-Spin Relaxation Times for Asphalt Ridge Tar Sand Bitumen in Various Solvents........

\section{LIST OF FIGURES}

Figure

Page

1. IH Spin-Lattice Relaxation Rate of Asphalt Ridge Tar Sand Bitumen as a Function of Time After Quenching........ 10

2. IH Spin-Lattice Relaxation Rate of Asphalt Ridge Tar Sand Bitumen as a Function of the Weight Fraction in

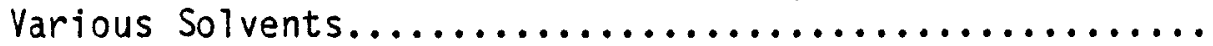

3. ${ }^{1} H$ Spin-Spin Relaxation Rate of Asphalt Ridge Tar Sand Bitumen as a Function of the Weight Fraction in Various Solvents... 
Investigations of the chemical association and molecular dynamics in fossil fuel materials using nuclear magnetic resonance relaxation spectroscopy have been done extensively for coal, less so for oil shales, and almost not at all for tar sand.

Preliminary studies on tar sand bitumen given in this report have shown that the reassociation of tar sand bitumen to its original molecular configuration after thermal stressing is a first-order process requiring nearly a week to establish equilibrium. The first-order rate constant was found to be $0.0139 \mathrm{hr}^{-1}$.

Preliminary studies were also conducted on the dissolution of tar sand bitumen in solvents of varying polarity. It was observed that at a high-weight fraction of solute to solvent the apparent molecular weight of the bitumen molecules was greater than that of the original bitumen when dissolved in chloroform- $d_{1}$ and benzene- $d_{6}$. This increase in the apparent molecular weight may be due to micellar formation or a weak solute-solvent molecular complex. Upon further dilution with any of the solvents studied, the apparent molecular weight of the tar sand bitumen decreased because of reduced van der. Waals forces of interaction and/or hydrogen bonding. However, to define the exact nature of the interactions, it will be necessary to have viscosity measurements of the solutions because the viscosity affects, in part, the relaxation measurements. 


\section{INTRODUCTION}

A fundamental understanding of the inter- and intramolecular interactions of organic molecules and the association of organic molecules with mineral matrices is paramount to the development of any viable commercial process for the extraction of tar sand bitumen as well as for the conversion of kerogen in oil shale to shale oil. These molecular interactions affect the mobility of molecules and, in turn, dictate the mechanical and thermal energy required for the conversion of the bitumen and kerogen to useful oil by-products.

Several types of molecular interactions are responsible for the chemical and physical properties of a complex mixture such as tar sand bitumen in its native state (tar sand ore) and tar sand bitumen in its free state (extracted bitumen). These molecular interactions include the long-range van der waals forces (dispersion, dipole-dipole, and dipole-induced dipole) and the short-range valence or chemical forces ( $H$-bonding and chemisorption). The strength of these interactions either between the organic constituents or organic constituents and the mineral matrix all depend, in part, upon the dipolar nature and intermolecular distances of the molecules.

One technique used in the investigation of mobility (molecular dynamics) and molecule associations (chemical association) in complex molecular systems is nuclear magnetic resonance (NMR) relaxation spectroscopy (Netzel and Miknis 1977). With this technique, the nuclear dipolar spin-lattice $\left(T_{1}\right)$ and spin-spin $\left(T_{2}\right)$ relaxation times are measured and used to investigate the mobility of molecules and molecuiar interactions.

The spin-lattice and spin-spin relaxation rates (the inverse of the relaxation times) can be derived from theoretical principles. Mathematically, the relaxation times are the product of a nuclear interaction constant, $k_{j}$ and a molecular correlation time, $\tau c$. The nuclear interaction constant for each relaxation rate is derived from a set of nuclear constants and molecular parameters that include the internuclear distances. The nuclear interaction constants are usually independent of temperature. The molecular correlation time can either be a measure of the time for a molecule to rotate one radian if the nuclear interaction is intramolecular or the time for a molecule to traverse one molecular diameter if the nuclear interaction is intermolecular. The molecular correlation times depend on the molecular weight and symmetry of the molecule, intermolecular interactions, viscosity, density and temperature, all of which affect the observed spin-lattice and spin-spin relaxation times.

There is little reported research on the characterization of the type and strength of the intermolecular interactions in fossil fuel materials. The rates of intermolecular association of molten asphalt were studied by Ensley (1975) using a sensitive microcalorimeter. Hydrogen bonding in coal-derived materials was reported in a series of papers by Tewari et a1. $(1978,1979,1984)$. Hydrogen bonding was also studied by Weyrin and Larsen (1983) and Young et al. (1984). 
Intermolecular forces in coal liquefaction product distillates were recently investigated by white and schmidt (1987) using average molar volume and average molar polarizability data. Though the evidence is not conclusive, van der Wals forces appear to be the dominate interactions in coals.

Recently NMR ${ }^{1} \mathrm{H}$ spin-lattice relaxation spectroscopy was used to study the mobility of hydrogen in solvent-swollen coals (Kamienski 1987), to identify the rigid and mobile components in coal structure (Tekely 1986; Jurkiewicz et al. 1987), and to delineate the thermoplastic behavior of coal during heating (Webster and Lynch 1981; Tekely et a1. 1987; Sakurovs et a1. 1987).

The temperature-dependent hydrogen $T_{1}$ values of oil shales were studied by Harrell and Kohno (1984) and by Miknis and Netzel (1976). Spin-spin relaxation times were reported by Lynch and Webster (1983) for Australian oil shales.

Miknis and Netzel (1976) also conducted a preliminary study on the spin-lattice relaxation time as a function of temperature for a tar sand ore and bitumen. Using both spin-lattice and spin-spin relaxation time measurements, Sobol et a1. (1985) concluded that the bitumen is composed of three phases: solid-like (rigid), solid-like (mobile), and semiliquid. They also concluded that water exists in two different environments, one in the bridges between the sand grains and the other on the clay surface.

inost of the reported research for tar sand bitumen is in the area of physicochemical characterization involving measuring the physical properties and identifying and quantifying compounds or compound types using chemical and spectroscopic techniques. Although important, the chemical characterization of tar sand bitumen provides little insight into the molecular interactions and mobility of molecules subjected to variations in temperature or solvent polarity.

An understanding of the associative properties of biturnen in its native state (tar sand ore) and in its free state (extracted bitumen) may provide the information to optimize in situ and above-ground thermal and solvent extraction processes. In addition, a knowledge of the associative properties may also provide insight for developing novel surfactant-type extraction processes or for developing environmental methods for site cleanup of residue materials.

The primary objective for the prograin is to investigate the chemical association and mobility of tar sand bitumen in its native state and in the free state by NMR relaxation spectroscopy. These investigations include the study of tar sand ore and bitumen when subjected to thermal stress and to solvents of different polarity. 


\section{EXPERIMENTAL}

\section{Sample Description}

Tar Sand Ore

The tar sand ore was obtained from the Asphalt Ridge site at the Uinta County quarry, Vernal, Utah. The ore, a composite of drums $6 \mathrm{~A}$ and $6 \mathrm{~B}$, had a bitumen content of $\sim 13.6 \%$.

\section{Tar Sand Bitumen}

The bitumen was obtained using a standard Soxhlet extraction technique for recovering organic materials from mineral matrices. The tar sand ore was wejghed into a glass extraction thimile and extracted with $700 \mathrm{~mL}$ of toluene until the solvent leaving the thimble was colorless. The fine mineral matter was filtered from the extraction solvent containing the organic material. The toluene was then removed by rotary evaporation. The remaining tar sand ore was extracted with $700 \mathrm{~mL}$ of pyridine for 24 hours. The bulk of the pyridine was removed by rotary evaporation. Traces of pyridine were removed by two azeotropic distillations with $\sim 50 \mathrm{~mL}$ of toluene. Previous experiments in which a simulated distillation technique was used showed that less than $1 \%$ by volume of solvent remained in the bitumen. All bitumen fractions were combined.

$\underline{\text { Coal }}$

The coal sample used was a high-volatile bituminous standard coal obtained from Alpha Resources, Inc., containing on a dried basis $0.90 \%$ sulfur, $9.24 \%$ ash, $36.17 \%$ volatile matter, $54.59 \%$ fixed carbon. It had a heating value of $13,187 \mathrm{Btu} / 1 \mathrm{~b}$.

\section{oil Shates}

The western reference shale is a Mahogany zone, Parachute Creek Member, Green River Formation oil shale obtained from the Exxon Colony mine located near Parachute, Colorado. The eastern reference shale is a Clegg Creek Member, New Albany shale obtained from the Knieriem Quarry, which is located approximately 16 miles south of the Ohio River at Louisville, Kentucky. Complete descriptions of the reference oil shales have been given in a report by Miknis and Robertson (1987).

The oil shale material was reduced to size by grinding to approximately 100 mesh and then riffled to obtain representative samples.

\section{Paraffin Wax}

The wax sample, obtained locally, was the type used in sealing preserves. 


\section{Solvents}

Benzene assayed at $99.9 \%$ was obtained from. MCB Manufacturing Chemists, Inc. Chlorobenzene assayed at $99.5 \%$ was obtained from Eastman Kodak Company. Carbon tetrachloride assayed at $99.8 \%$ was obtained from J. T. Baker Chemical Co. Chloroform-d $d_{1}$ assayed at 99.8 atom $\%$ of deuterium was obtained from Cambridge Isotope Laboratories. Benzene$d_{6}$ and Pyridine- $d_{5}$ assayed at 99.5 and 99.0 atom $\%$ of deuterium, respectively, were obtained from Norell Chemical Co., Inc.

A11 samples were used as received and without degassing.

\section{Instrumentation}

An IBM PC-20 spectrometer with a 4.7-kg fixed magnet and an oscillating field of $20 \mathrm{MHz}$ for hydrogen was used for all NMR experiments. The temperature of the magnet and probe assembly was held constant at $40^{\circ} \pm 0.01^{\circ} \mathrm{C}\left(104^{\circ} \mathrm{F}\right)$. A $7.5-\mathrm{mm}$ variable temperature solid/liquid probe was used but modified by placing a $1-\mathrm{cm}$ Teflon spacer in the bottom of the probe assembiy. This spacer was used to ensure that the samples were within the $20-\mathrm{mm}$ coil height when placed in a $7.5-\mathrm{mm}$ flat bottom NMR tube. The spectrometer was operated in the phase-sensitive detector mode with the bandwidth set at high for all relaxation time experiments. The number of transients averaged to ensure good signalto-noise ratio varied from 4 to 100 depending upon the sample. The attenuation was set at a value of 39 and the delay time between pulse sequences was set at 5 and 10 seconds for spin-lattice and spin-spin relaxation time, respectively.

The inversion-recovery $(\pi-\tau-\pi / 2)$ technique and an iterative, nonlinear, three-parameter curve fit were used to obtain the spin-lattice relaxation times, $T_{1}$. Equation 1 was used for the calculation:

$$
M_{\tau}=M_{\infty}\left(1-\partial e^{-\tau / T_{1}}\right)
$$

where, $M_{\tau}=$ the intensity at a pulse delay time of $\tau$

$\tau^{\tau}=$ pulse delay time between $\pi$ and $\pi / 2$ pulses

$\theta=$ flip angle

$M_{\infty}=$ the intensity at infinite $\tau$ (single $90^{\circ}$ pulse)

The Carr-Purcell-Meiboom-Gill technique (CPMG) and a nonlinear, two-parameter curve fitted to equation 2 were used to obtain the spinspin relaxation times, $T_{2}$.

$$
M_{\tau}=M_{\infty} e^{-\tau / T} 2
$$




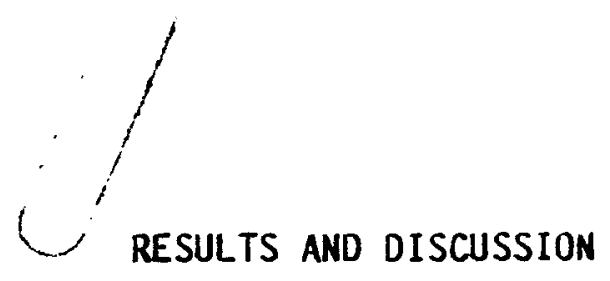

\section{Hydrogen $T_{1}$ Values of Related Materials}

To validate the instrumental and operational conditions used to obtain $T_{1}$ and $T_{2}$ values, several different types of materials were studied. In Table 1 the ${ }^{1} H$ spin-lattice relaxation times are listed for pure compounds (benzene, chlorobenzene, and water), a paraffin wax, and several fossil fuels (coal, western and eastern reference oil shales, and the Asphalt Ridge tar sand ore and bitumen). Reported values for the hydrogen spin-lattice relaxation times for benzene and chlorobenzene at $40^{\circ} \mathrm{C}\left(104^{\circ} \mathrm{F}\right)$ are not readily available. However, the $T_{1}$ value of water (deionized) at $40^{\circ} \mathrm{C}$ has recently been reported by Schmidt et al. (1986) using a PC-20 spectrometer. The value reported was $3.34 \pm 0.02$ $\mathrm{sec}$, which compares favorably with the value of $3.98 \pm 0.01 \mathrm{sec}$ listed in the table.

Woessner (1964) reported the hydrogen spin-lattice relaxation times for several liquid n-alkanes. He obtained a value of $1.0 \mathrm{sec}$ for $n$ hexadecane. The trend in the ${ }^{1} H T_{l}$ values reported for $n$-alkanes shows a decrease in $T_{1}$ with increasing molecular weight. Thus a value of 0.19 sec listed in Table 1 for the spin-lattice relaxation time of solid paraffin $(C>20)$ is not unreasonable.

The ${ }^{1} H$ spin-lattice relaxation times for coals were measured by Sullivan et al. (1983). The $T_{1}$ values ranged from 8 to 103 msec depending upon the rank of the coal. The $T_{1}$ value listed in Table 1 for the coal sample falls well within the range reported in the literature.

The spin-lattice relaxation time for a western oil shale was reported by Harrell and Kohno (1984) and by Miknis and Netzel (1976). The $T_{1}$ values in the literature for western oil shale differ from the measured value listed in Table 1, but this may be due to the different sources of the western oil shale. Essentially no difference was noted for the eastern oil shale between the $T_{1}$ values reported in this work and the value reported in the literature.

The value in the literature for $T_{1}$ of a tar sand ore and bitumen was estimated from the plot of $T_{1}$ versus temperature given in the paper by Miknis and Netzel (1976). The $T_{1}$ values of the Asphalt Ridge tar sand ore and bitumen reported in Table 1 are in close agreement with the estimated values in the literature.

Aside from the reported $T_{1}$ value for water, all other reported $T_{1}$ values were measured using either a different type of instrument or technique. From the close agreement of the $T_{1}$ values reported here for the widely different materials with those reported in the literature, it was concluded that both the instrumental and operational techniques could be used in subsequent $T_{1}$ and $T_{2}$ studies of the kinetics and solvent effects on the chemical association in tar sands even though $\mathrm{T}_{2}$ values were not readily available in the literature. 
Table 1. 1H Spin-Lattice and Spin-Spin Relaxation Times for Various Materials

\begin{tabular}{|c|c|c|c|}
\hline Material & \multicolumn{2}{|c|}{$\begin{array}{c}\text { Spin-Lattice Relaxation } \\
\text { Time, } T_{1}, \text { sec }^{2}\end{array}$} & $\begin{array}{c}\text { Spin-Spin Relaxaţion } \\
\text { Time, } T_{2} \text {, sec } \\
\text { This Work }\end{array}$ \\
\hline Benzene & $4.452 \pm 0.018$ & N.F. b $^{-}$ & $0.646 \pm 0.009$ \\
\hline Chlorobenzene & $3.867 \pm 0.026$ & N.F. & \\
\hline Water (deionized) & $3.983 \pm 0.006$ & $3.84 \pm 0.02^{C}$ & $0.564 \pm 0.005$ \\
\hline Wax & $0.191 \pm 0.005$ & $1.0^{d}$ & \\
\hline Coal & $0.038 \pm 0.004$ & $0.008-0.103^{\mathrm{e}}$ & \\
\hline Western Reference 0 il Shale & $0.058 \pm 0.004$ & $\begin{aligned} 0.014^{f} & , 0.025^{g} \\
& 0.100^{h}\end{aligned}$ & \\
\hline Eastern Reference 0il Shale & $0.003^{i}$ & $0.004^{f}$ & \\
\hline Asphalt Ridge Tar Sand Ore & $0.052 \pm 0.002$ & $0.056^{\mathrm{g}}$ & \\
\hline Asphalt Ridge Tar Sand Bitumen & $0.062 \pm 0.000$ & $0.056^{g}$ & \\
\hline
\end{tabular}

\footnotetext{
Measured at $40^{\circ} \mathrm{C}$

$b_{\text {Not found }}$

Schmidt et al. (1986)

Woessner (1964)

Sullivan et al. (1983)

$f_{\text {Harrell et al. (1983) }}$

Miknis and Netzel (1976)

$h_{\text {Sydansk (1978) }}$

$i_{\text {Estimated from the null method }}$
} 
Chemical Association Kinetics for Tar Sand Ore and Bitumen AfterThermal Stressing

The Asphalt Ridge tar sand ore and the extracted bitumen samples were placed in an NMR tube and heated to $180^{\circ} \mathrm{C}\left(356^{\circ} \mathrm{F}\right)$ in a fluidized sand bath (Conn et al. 1984) for 1 hour. The samples were removed and quenched in water at $\sim 21^{\circ} \mathrm{C}\left(70^{\circ} \mathrm{F}\right)$. The samples were then placed in the NMR spectrometer and allowed to equilibrate at $40^{\circ} \mathrm{C}\left(104^{\circ} \mathrm{F}\right)$ before the relaxation time was measured. The samples were removed and stored at ambient temperature until the next measurement in which the sample was again heated to $40^{\circ} \mathrm{C}\left(104^{\circ} \mathrm{F}\right)$ before the relaxation measurement was taken.

The IH spin-lattice relaxation times for the tar sand ore and bitumen at various times after quenching are listed in Table 2. The $T_{1}$ values for the tar sand ore are highly scattered with no obvious trend in the data. However, the $T_{1}$ values for the tar sand bitumen show a definite decrease with time, approaching the initial value after nearly a week.

For a nonviscous molecular system consisting of small spherical molecules tumbling isotropically, the molecular rotational correlation time, $\tau$, is related to the intramolecular dipolar spin-lattice relaxatfon time, $T_{1}$, as given by equation 3 (Farrar and Becker 1971):

$$
R_{1}=\frac{1}{T_{1}}=\frac{\hbar^{2} \gamma_{H}^{4} \tau_{C}^{r}}{r_{H H}^{6}}
$$

where, $R_{1}=$ the intramolecular dipolar spin-lattice relaxation rate

$\bar{n},=$ Plank's constant divided by $2 \pi$

$\gamma_{H}=$ the magnetogyric ratio for the ${ }^{1} \mathrm{H}$ nucleus

$r_{H H}=$ the $H-H$ intranuclear distance.

A physical description of the motions of a molecule is contained in the molecular correlation time. The correlation time depends on the molecular weight and symmetry of the molecule, the viscosity, density and the temperature which, in turn, affects the spin-lattice relaxation rate. A measure of the relaxation rate gives only the "mean" or "effective" correlation time and, thus, a description of the molecular dynamics of molecules in solution requires that the correlation time be related to some physical model describing molecular motion. One such model consists of calculating the rotational diffusion constant for the reorientation of a molecule in random steps of small angular displacement using the Stokes-Einstein equation (Lyerla 1971).

The derivation of the relationship of the relaxation rate, $R_{1}$, as a function of molecular parameters (equation 4) is given in the thesis by Netzel (1975) and references cited therein.

$$
R_{1}=k_{p}[M n / T \rho]
$$


Table 2. ${ }^{1}$ H Spin-Lattice Relaxation Times After Quenching of Asphalt Ridge Tar Sand Ore and Bitumen Heated to $180^{\circ} \mathrm{C}$ for 1 Hour

\begin{tabular}{|c|c|c|}
\hline $\begin{array}{l}\text { Time After } \\
\text { Quenching, } \\
\text { hours } \\
\end{array}$ & $\begin{array}{l}\text { Tar Sand Ore } \\
\text { Spin-lattice } \\
\text { Relaxation Time, } \\
\text { sec }^{a} \\
\end{array}$ & $\begin{array}{c}\text { Tar Sand Bitumen } \\
\text { Spin-lattice } \\
\text { Relaxation Time, } \\
\sec ^{\alpha} \\
\end{array}$ \\
\hline $\begin{array}{r}0.00 \\
0.18 \\
0.75 \\
1.50 \\
5.83 \\
17.75 \\
18.50 \\
26.00 \\
29.33 \\
41.91 \\
42.70 \\
50.60 \\
53.91 \\
66.24 \\
66.85 \\
78.27 \\
90.24 \\
90.85 \\
102.85 \\
115.18 \\
116.24 \\
139.39 \\
187.18\end{array}$ & $\begin{array}{l}0.0519 \mathrm{~b} \\
0.0528 \\
0.0499 \\
0.0532 \\
\\
0.0482 \\
0.0504 \\
\\
0.0470 \\
0.0521 \\
\\
0.0527 \\
\\
0.0506 \\
0.0502\end{array}$ & $\begin{array}{l}0.0615^{b} \\
0.0646 \\
0.0647 \\
\\
0.0641 \\
0.0632 \\
\\
0.0630 \\
0.0624 \\
\\
0.0615 \\
0.0623 \\
0.0623 \\
0.0614 \\
0.0613 \\
0.0608\end{array}$ \\
\hline
\end{tabular}

a Measured at $40^{\circ} \mathrm{C}$

Before heating to $180^{\circ} \mathrm{C}$ 
where $M=$ the molecular weight

$n=$ viscosity

$\rho=$ density

$T=$ temperature

$k_{p}=$ the proportionality constant

To a first approximation, equation 4 may be used to explain the data for tar sand bitumen given in Table 2. The relaxation rate as a function of time for the tar sand bitumen is shown in figure 1 . The increase in the relaxation rate suggests that the molecular weight and/or viscosity is increasing with time after quenching (see equation 4). It can be assumed that at $180^{\circ} \mathrm{C}\left(356^{\circ} \mathrm{F}\right)$, the tar sand bitumen is partially dissociated relative to ambient temperature, that is, a reduction of the van der waals forces and/or hydrogen bonding occurs. The dissociated state of the tar sand bitumen is "frozen" by quenching the system to room temperature. Reassociation of the tar sand bitumen molecules begins after quenching and continues for nearly a week before equilibrium is reestablished.

The solid line in Figure 1 represents the best statistical fit of the data for a first-order rate equation of the form

$$
R_{1}^{t}=R_{1}^{0}+\left(R_{1}^{\infty}-R_{1}^{0}\right)\left(1-e^{-k t}\right)
$$

where $R_{1}^{t}, R_{1}^{0}$ and $R_{1}^{\infty}$ are the spin-lattice relaxation rates at time $t$, zero time, and infinite time (initial value before heating), respectively. $t$ is the time in hours and $k$ is the first-order rate constant.

The correlation coefficient, $r^{2}$, for the data was found to be 0.965. The calculated values for $R_{1}$ and $R_{1}^{\infty}$ were determined to be $15.45 \mathrm{sec}^{-1}$ and $16.50 \mathrm{sec}^{-1}$, respectively, and the first-order rate constant for the reassociation was found to be $0.0139 \mathrm{hr}^{-1}$.

\section{Solvent-Solute (Tar Sand Bitumen) Interaction}

The spin-lattice and spin-spin relaxation times were measured for various weight fractions of tar sand bitumen dissolved in solvents of different polarity. These values are listed in Table 3 for the bitumen in chloroform- $d_{1}$, carbon tetrachloride, benzene- $d_{6}$ and pyridine- $d_{5}$.

It is known that tar sand bitumen solubility depends on the polarity of the solvent. The solvation depends upon the disruption of the van der Waal intermolecular forces and hydrogen bonding. The relative extent to which the molecular interactions of a solute are increased or reduced by different solvents can be determined from NMR relaxation studies in which nonhydrogen-containing or deuterated solvents are used to avoid interference with the ${ }^{1} H$ relaxation rate measurements of the solute. Changes in the relaxation rate of the tar sand bitumen as a function of its weight fraction in solution can be 


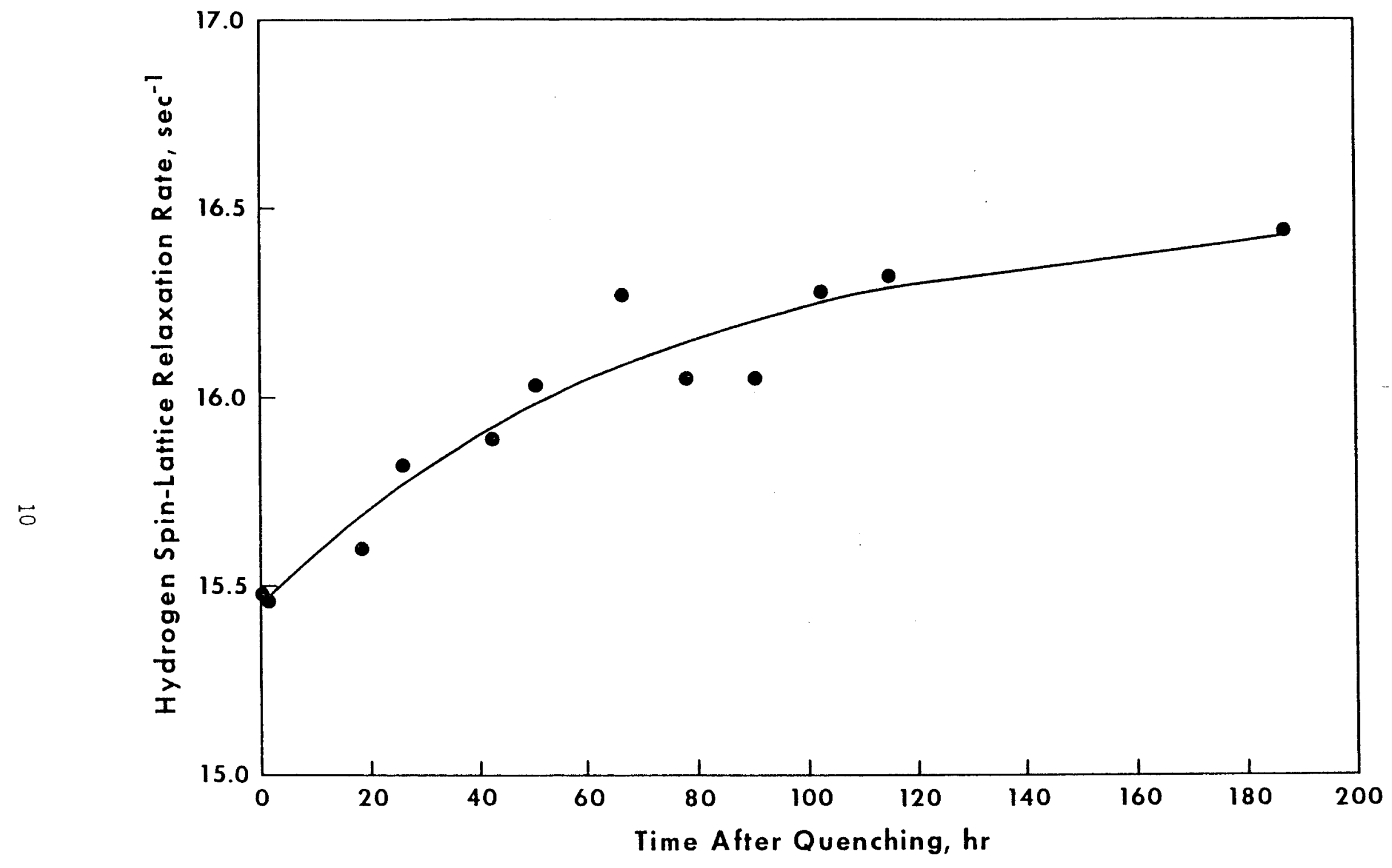

Figure 1. ${ }^{1}$ H Spin-Lattice Relaxation Rate of Asphalt Ridge Tar Sand Bitumen as a Function of Time After Quenching 
Table 3. IH Spin-lattice and Spin-Spin Relaxation Times for Asphalt Ridge Tar Sand Bitumen in Various Solvents

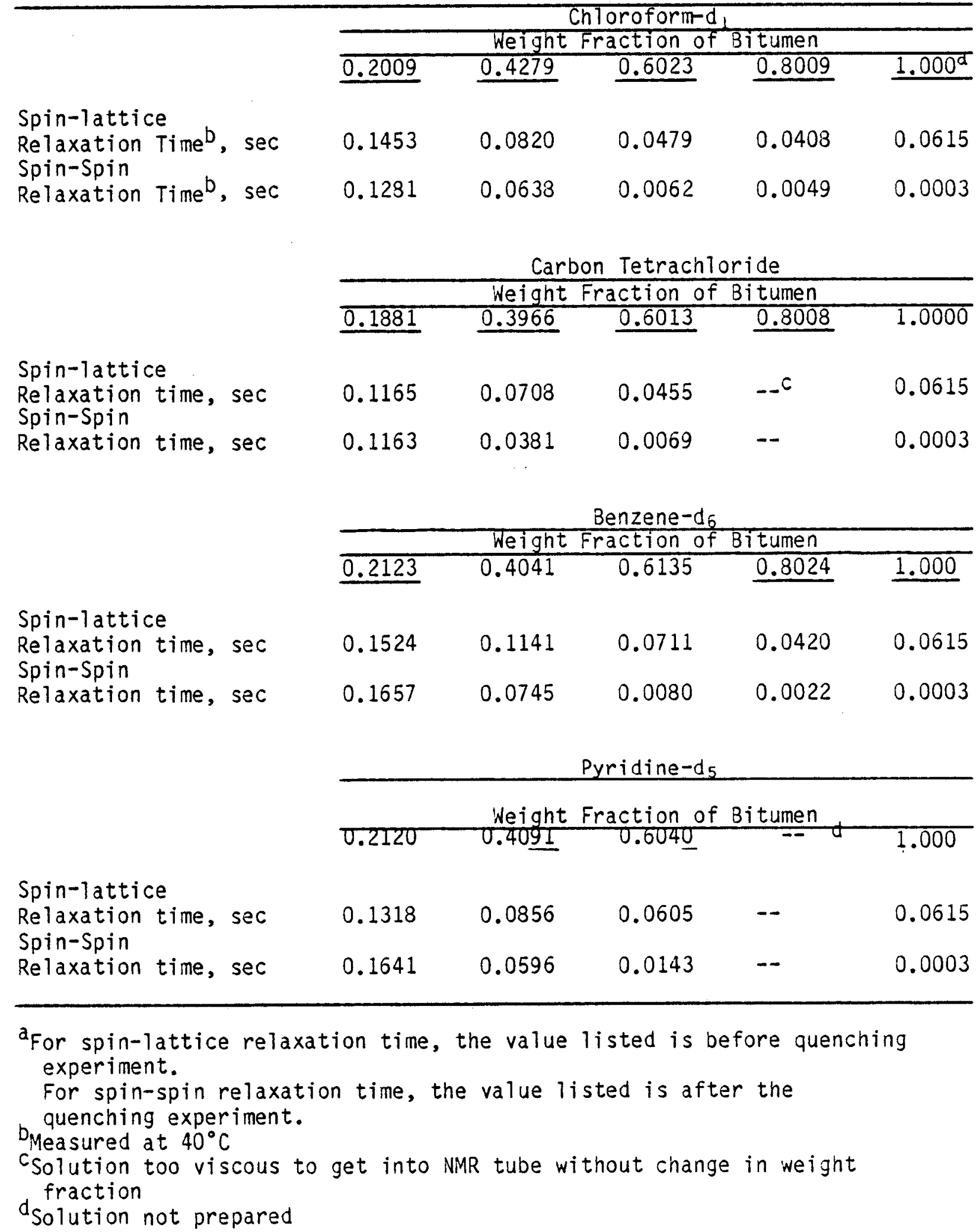


attributed to changes in the molecular structure caused by solute-solute and/or solute-solvent interactions. These interactions can result in the formation of micelles, complexation, and/or solvation of the solute by the solvent.

As previously mentioned, the relaxation rate is directly related to the molecular weight of the molecular moiety. If this argument is pursued further, the data in Table 3 and Figure 2 can be explained on the basis that the molecular weight of molecular moiety changes upon dilution with a solvent and that the relative change depends on the polarity of the solvent.

It appears from the data presented in Figure 2 that there is an initial increase in the relaxation rate followed by an almost uniformal decrease upon dilution with each of the solvents. The initial increase in the relaxation rate for the tar sand bitumen in chloroform- $d_{1}$ and benzene- $d_{6}$ (only solvents for which data are available) may be due to an increase in the apparent molecular weight and/or viscosity of the solution. If it is due to an increase in the apparent molecular weight through association, the molecular moiety may be the result of the formation of "micelles" or weak solute-solvent complexes. Upon further dilution, the van der waals intermolecular forces and hydrogen bonding decrease, resulting in smaller molecular fragments. The decrease in the relaxation rate with increasing dilution may also be due to a decrease in the viscosity of the solution (see equation 4).

For a weight fraction of bitumen in any solvent less than 0.6 , the molecular weight of the molecular species present is less than in the original starting material providing viscosity is not a factor. The chemical association in the solutions cannot be ascertained until viscosity measurements are made. Also from Figure 2, it appears that benzene is a better solvent for the dissolution of tar sand bitumen than any of the other solvents studied as seen by the smaller relaxation rate (smaller molecules) for a given weight fraction.

The changes in the spin-spin relaxation rates of tar sand bitumen at various weight fractions in various solvents are shown in Figure 3. Information on the spin-spin relaxation rate of tar sand bitumen without any solvents could not be obtained with the instrumental configuration used in these experiments. The arguments presented in the previous section on spin-lattice relaxation rate of tar sand bitumen in solution also apply to the spin-spin relaxation data.

\section{CONCLUSIONS}

Nuclear magnetic resonance spectroscopy can be a useful technique in the investigation of intermolecular interactions and molecular mobility. It was found that tar sand bitumen when subjected to thermal stress followed by quenching requires almost a week at $40^{\circ} \mathrm{C}\left(104^{\circ} \mathrm{F}\right)$ for the molecular species to reassociate to an equilibrium molecular configuration. The reassociation was found to be first-order with a rate constant of $0.0139 \mathrm{hr}^{-1}$. 


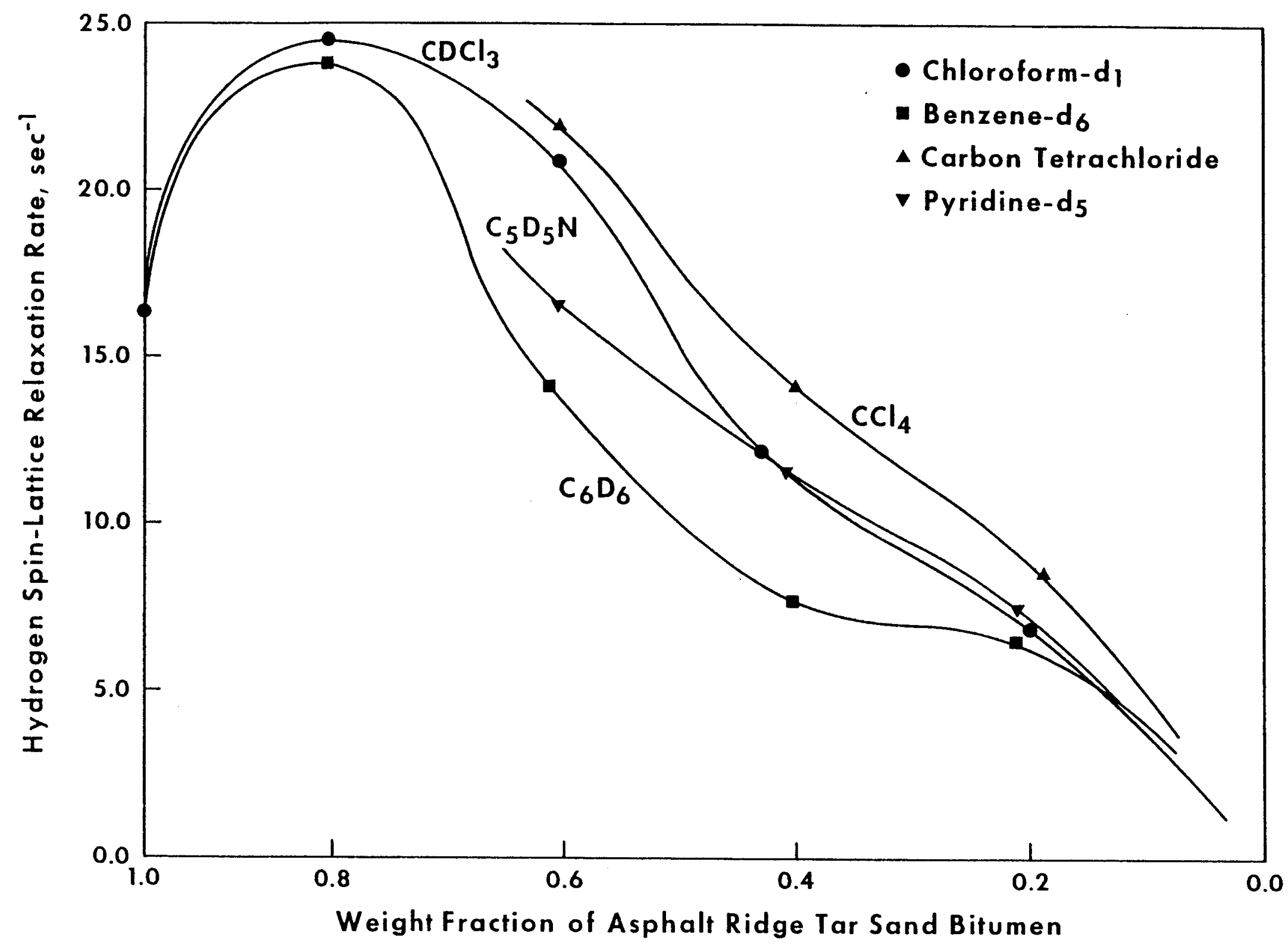

Figure 2. ${ }^{1} H$ Spin-Lattice Relaxation Rate of Asphalt Ridge Tar Sand Bitumen as a Function of the Weight Fraction in Various Solvents 


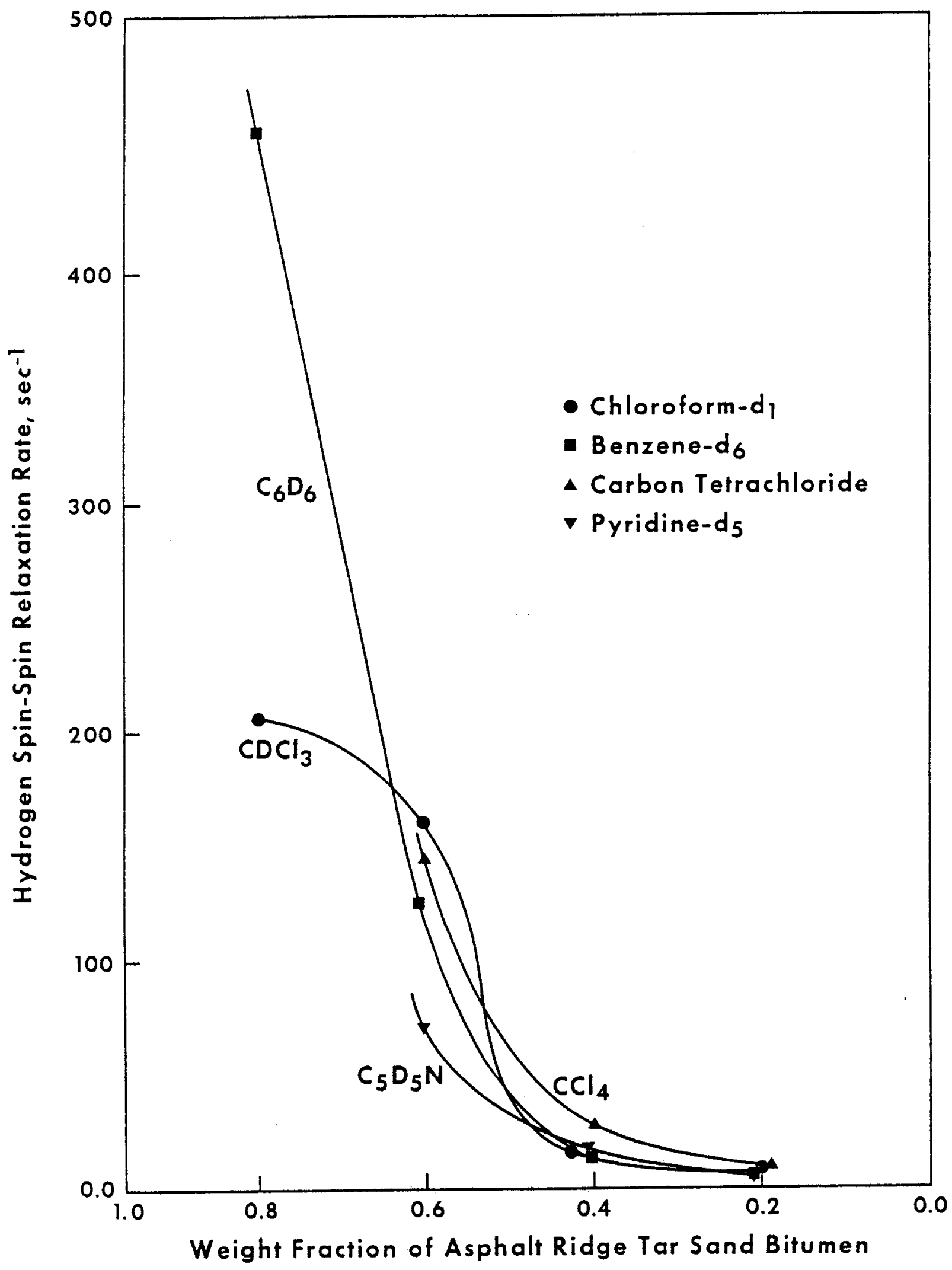

Figure 3. ${ }^{1} H$ Spin-Spin Relaxation Rate of Asphalt Ridge Tar Sand Bitumen as a Function of the Height Fraction in Various Solvents 
It was also found that spin-lattice and spin-spin relaxation time measurements can be used to investigate the different degrees of association of tar sand bitumen dissolved in solvents of different polarity. Additional experiments are needed to ascertain if the preliminary results are caused by changes in intermolecular association of the molecular species or by changes in the viscosity of the solutions.

\section{ACKNOWLEDGMENT}

The authors express thanks and appreciation to the United States Department of Energy for funding of this work under Cooperative Agreement Number DE-FC21-83FE60177 and to F. Turner for the statistical treatment of the kinetic data.

\section{DISCLAIMER}

Mention of specific brand names or models of equipment is for information only and does not imply endorsement.

\section{REFERENCES}

Conn, P. J., H. J. Rollison, and F. P. Miknis. "Comparison of Isothermal Kerogen Decomposition Results Using Reactors with Difference Heat-Up Rates," Laramie, WY, October 1984, DOE/FE/601771791.

Ensley, E. K. "A Kinetic Investigation of Association in Asphalt," J. Coll. and Inter. Sci., 1975, 53, 452-60.

Farrar, T. C., and E. D. Becker. Pulse and Fourier Transform NMR, Academic Press: New York, 1971.

Harre11, J. W., Jr., and T. Kohno. "Temperature-Dependent Proton $T_{1}$ and $T_{1}$ Study of $0 i 1$ Shales," in Magnetic Resonance; L. Petrakis and J. P. Fraissard, Eds.; D. Reidel Publishing Co.: Boston, MA, $1984,597-606$.

Jurkiewicz, A., S. Idziak, and N. Pislewski. "lH NMR Spin-Lattice Relaxation Study in Bituminous Coal," Fuel, 1987, 66, 1066-8.

Kamienski, B., M. Pruski, and B. C. Gerstein. "Mobilities of Hydrogen in Solvent-Swollen Coals. A Study by Pulsed NMR," Energy and Fue 1s, $1987,1,45-50$.

Lyerla, Jr., J. R., "Elucidation of Carbon-13 Spin-Lattice Relaxation Mechanisms," Ph.D. Dissertation, University of Utah, Salt Lake City, Utah, 1971. 
Lynch, L. J., and D.S. Webster. "IH-NMR Thermal Scanning Methods for Studying 0il Shale Pyrolysis," in Geochemistry and Chemistry of 0il Shales; F. P. Miknis and J. F. McKay, Eds.; ACS Symposium Series 230, American Chemical Society: Washington, DC, 1983.

Miknis, F. P., and D. A. Netzel. "NMR Studies of $0 i 1$ Shales and Related Materials," in Magnetic Resonance in Colloid and Interface Science; H. A. Resing and C. G. Wade, Eds.; ACS Symposium Series 34, American Chemical Society: Washington, DC., 1976.

Miknis, F. P., and R. E. Robertson. "Characterization of DOE Reference 0il Shales: I Mahogany Zone, Parachute Creek Member, Green River Formation 0il Shale, and Clegg Creek Member, New Albany Shale," DOE report in preparation.

Netze1, D. A. "I. Carbon-13 Chemical Shifts and Spin-Lattice Relaxation Times of Saturated Heterocycles. II. NMR Relaxation Studies of Nitrogen-15," Ph.D. Dissertation, Northwestern University, Evanston, IL, 1975. Available: Xerox University Microfilms, Ann Arbor, MI 48106.

Netzel, D. A., and F. P. Miknis. "Nuclear Spin Relaxation Spectroscopy," App1. Spectros., 1977, 31, 365-86.

Sakurovs, R., L. J. Lynch, T. P. Maher, and R. N. Banerjee. "Molecular Mobility During Pyrolysis of Australian Bituminous Coals," Energy and Fuels, $1987,1,167-72$.

Schmidt, E. J., K. K. Velasco, and A. M. Nur. "Quantifying Solid-Fluid Interfacial Phenomena in Porous Rocks with Proton Nuclear Magnetic Resonance," J. Appl. Phys., 1986, 59, 2788-97.

Sobol, W. T., L. J. Schreiner, L. Miljkovic, M. E. Marcondes-Helene, L. W. Reeves, and M. M. Pintar. "NMR Line Shape-Relaxation Correlation Analysis of Bitumen and $0 i 1$ Sands," Fue 1, 1985, 64, 583-90.

Sullivan, M. J., N. M. Szeverenyi, G. E. Maciel, L. Petrakis, and D. W. Grandy. "Proton Spin-Lattice Relaxation in Coals of Varying Rank," in Magnetic Resonance; L. Petrakis and J. P. Fraissard, Eds.; D. Reidel Publishing Co.: Boston, MA, 1984.

Sydansk, R. D. "Colorado Green River Formation 0il Shale as Viewed by Pulsed NMR," Fuel, 1978, 57, 66-72.

Tekely, P., D. Nicole, J. Brondeau, and J.-J. Delpuech. "Application of Carbon-13 Solid-State High Resolution NMR to the Study of Proton Mobility. Separation of Rigid and Mobile Components in Coal Structure," J. Phys. Chem., 1986, 90, 5608-11.

Tekely, P., D. Nicole, and J.-J. Delpuech. "13C CP/MAS NMR Study of Changes in Molecular Mobility of Coal After Pyrolysis at $590^{\circ} \mathrm{C}$," Energy and Fuels, 1987, 1, 121-22. 
Tewari, K. C., L. G. Galya, K. M. Egan, and N. C. Li. "Calorimetric Study of Quinoline Interaction with o-phenylphenol and Coal-Derived Asphaltenes," Fuel, 1978, 57, 245-9.

Tewari, K. C., K. M. Egan, and N. C. Li. "Characterization of CoalLiquid Fractions. Molar Enthalpies of Quinoline Interaction with Coal-Derived Asphaltenes and Heavy 0i1s," Fue1, 1978, 57, 712-16.

Tewari, K. C., T. Hara, L. J. S. Young, and N. C. Li. "Influence of Hydrogen Bonding on the Viscosity of Coal Liquids," Fuel Process Technol., 1979, 2, 303-11.

Tewari, K. C., N-S Kan, D. M. Susco, and N. C. Li. "Viscosity, Calorimetric, and Proton Magnetic Resonance Studies on Coal Liquid Fractions in Solution," Anal Chem., 1979, 51, 182-5.

Tewari, K. C., and N. C. Li. "On Molecular Interactions Involving CoalDerived Asphaltenes," Am. Chem. Soc. Div. Petrol. Chem., Prepr., $1979,24,982-9$.

Tewari, K. C., P. Stein and N. C. Li. "Heats of Interaction Between Coal-Liquid Fractions and Acids or Bases. Application of the Bolles-Drago Approach to Mixtures," Fuel, 1984, 63, 573-4.

Webster, D. S., and L. J. Lynch. "lH Nuclear Spin-Lattice Relaxation in Coal During Heating," Fuel, 1981, 60, 549-51.

Woessner, D. E. "Proton Spin-Lattice Relaxation of n-Paraffins in Solution," J. Chem. Phys., 1964, 41, 84-5.

Weyrich, 0. R., and J. W. Larson. "Thermodynamics of Hydrogen Bonding in Coal-Derived Liquids. Failure of the Bolles-Urago Approach Applied to Mixtures," Fuel, 1983, 62, 976-9.

White, C. M., and C. E. Schmidt. "Polarizability of Coal Liquefaction Product Distillates-Insight into Intermolecular Forces," Fuel, $1987,66,1030-5$.

Young, L. J. S., T. Hara, and N. C. Li. "Hydrogen Bonding of the Acid and Base Fractions Separated from SRCII Middle Distillates," Fuel, 1984, 63, 816-19. 
